\title{
To save the sun for a rainy day and to save the rain for a sunny day
}

\author{
Santanu Bandyopadhyay
}

Published online: 6 December 2014

(c) Springer-Verlag Berlin Heidelberg 2014

In October 2013, California's Public Utilities Commission adopted an energy storage mandate. The mandate required various California's investor-owned utilities to expand their energy storage capacity to gigawatt (GW) level. According to the Commission, the mandate was based on three basic objectives: optimization of the grid, generation and integration of renewable-based electricity production, and reduction of harmful greenhouse gases.

One of the major objectives of grid optimization is to improve capacity factor or plant load factor of power plants operating on fossil fuel, coal, oil or natural gas. Due to variation in demand, power plants have to run in part load condition, and part load operations of these plants are energy-inefficient.

Generation of electric power from various renewable sources is extremely important for developing overall sustainable energy system. Renewable power plants efficiently utilize natural energy resources such as solar radiation, wind, rain, tides, and biomass which are replenished naturally. It has already been proven that renewable power plants are economic in providing electrical power to remote places where grid extension is not possible. Unfortunately, renewable energy sources are intermittent, variable, and unpredictable. This leads to further mismatch between the renewable power generation and electricity demand.

It is important to match the generation and the demand to achieve an efficient energy system. This calls for two complementary approaches. First, modify the demand itself to suit the generation pattern. Segregation of demands, based on their priority, leads to the concept of a smart grid.

S. Bandyopadhyay $(\bowtie)$

Department of Energy Science and Engineering, Indian Institute of Technology Bombay, Powai, Mumbai 400076, India e-mail: santanub@iitb.ac.in
A smart grid uses information about the behaviors of generation and demand to improve the efficiency and reliability of the distribution and utilization of electrical energy. This can be extended for the entire energy system. Second, use of an energy storage system to synchronize between energy generation and energy utilization. In general, storage system stores energy whenever the collected energy is in excess of the demand and supplies energy to meet the demand whenever the collected energy is inadequate to meet the demand.

Energy storage is important to integrate inherently variable renewable resources with end-use sectors; to improve stability, flexibility, and reliability of the energy supply chain; to improve overall energy system efficiency, etc. Important energy storage options are pumped-hydro for hydroelectricity (water is stored in reservoir during low demand period); compressed air systems; flywheel system; thermal energy storage through storing sensible or latent heat; electrochemical storage using rechargeable batteries, ultra and flow batteries, and super-capacitors; hydrogen, etc. Batteries are successfully applied for small-scale applications. Cars, smartphones, laptops, and many other electronic gadgets store energy using rechargeable batteries. But large-scale usages of various storage options are not wide spread. There are two major deficiencies: overall conversion efficiency and duration of storage. Overall conversion efficiency, incorporating losses during storing and extracting, during charging and discharging, for most of these energy storage options is low. Furthermore, most of the economically viable options are for limited time period only. Due to various self discharges and continuous losses, effective lives for these options are low.

Not only for energy system, storage is important for developing any overall sustainable system. We need to store water, through rain water harvesting and other means 
to develop sustainable water system. We need to store food grains and other livestock to achieve sustainable agricultural system. In a nutshell, we need to save the sun for the night, and for the rainy season; we need to save each and every rain drop for the dry season. We are looking for a paradigm shift in storage technologies to promise a better world to the next generation. 